\title{
sciendo
}

Transport and Telecommunication, 2020, volume 21, no. 1, 69-83

Transport and Telecommunication Institute, Lomonosova 1, Riga, LV-1019, Latvia

DOI 10.2478/ttj-2020-0006

\section{BLUE GROWTH POTENTIAL IN SOUTH BALTIC SEA REGION}

\author{
Robert Philipp $^{1,2}$, Gunnar Prause ${ }^{1,2}$, Christopher Meyer ${ }^{1,2}$ \\ ${ }^{1}$ TALTECH University \\ Ehitajate tee 5, 12616 Tallinn, Estonia \\ ${ }^{2}$ Hochschule Wismar, University of Applied Sciences: Technology, Business and Design \\ Philipp-Müller-Str. 14, 23966 Wismar, Germany \\ robert.philipp@hs-wismar.de \\ gunnar.prause@taltech.ee \\ christopher.meyer@hs-wismar.de
}

\begin{abstract}
The Baltic Sea Region (BSR) stands for a flagship maritime region in Europe with dominating SME sector. Nevertheless, compared with other European regions, the cooperation and promotion activities of companies that belong to the Blue Economy in South Baltic Sea Region (SBSR) are not sufficient. As a response to this, the EU-project INTERMARE South Baltic aims to support the maritime economy in the SBSR by the creation of a network of companies and stakeholders.

In line with the project, this study aims to analyse the future potential of the maritime economy and to identify trends that impact the sustainable development of the blue sector in SBSR. Based on primary data from a SBSR wide survey, descriptive statistical analysis is applied and Compound Annual Growth Rate is used as an indicator. The findings reveal need for actions regarding the sub-sectors Transport, Offshore oil \& gas, Aquaculture, Fishery, Mineral resources and Biotechnology.
\end{abstract}

Keywords: Maritime Economy, Blue Growth, Sustainable Development, SMEs, Internationalisation, Predictive Analysis

\section{Introduction}

If all economic activities that depend on the sea would be cumulated, the so-called "Blue Economy" of the EU is responsible for about 5.4 million jobs and a gross value added of almost 500 billion EUR per year (EC, 2012). Thereby, especially the Baltic Sea Region (BSR) has still a forerunner position and thus, stands for a flagship maritime region in Europe in terms of good economic, social and environmental performance (Gerlitz et al., 2017). Following the current "State of the Region Report" (Ketels et al., 2017), the BSR generated in 2015 an annual GDP of about 2,000 billion EUR, which is equivalent to $12.5 \%$ of the EU-28 economy. Therefore, also in the South Baltic Sea Region (SBSR), the maritime economy is one of the most prospective area of development. However, compared with other European regions, the cooperation and promotion activities of companies that belong to the Blue Economy in the SBSR are not sufficient, which impairs the competiveness and sustainable development of the entire region. Furthermore, despite the strong lobbing and support coming from the regional authorities for the intensive development of the maritime economy and industries, there is still a lack of international instruments in the SBSR that support the internationalisation activities of SMEs.

As a response to this, the EU-project INTERMARE South Baltic - part-financed by the ERDF (INTERREG South Baltic Programme 2014-2020) - aims to support the maritime economy in the SBSR by the creation of a network of companies and stakeholders under the common brand "INTERARE South Baltic", which will be easily recognised in the region and in other European and global markets. In order to push forward this primary objective, within the EU-project INTERMARE South Baltic, companies from the SBSR that belong to the maritime economy - which we define in accordance to the EU Blue Growth Strategy - were surveyed.

In line with the project, the present study with a focus on SMEs aims to identify and analyse (1) the future potential of the maritime economy in SBSR in relation with the demand from other markets outside the region, and (2) potential trends that have an impact on the sustainable development of the blue sector in SBSR. Hence, the present study grounds on the survey from the EU-project INTERMARE South Baltic, and thus, reveals the empirical results thereof, which leads to the achievement of the envisaged objective of identification and analysis of the future potential as well as trends that affect the Blue Economy in the SBSR. 
The paper is structures as follow: In the second chapter, the theoretical background is drawn. The third section presents the applied research methodology, which includes an exposition of the data collection procedure, the data analysis measures as well as sample description. Building upon this, the main research results are showcased in the fourth chapter, which embraces a detailed analysis of the future potential of the blue sector as well as potential arising market trends that affect the maritime economy in the SBSR. The paper rounds up with a discussion and conclusion.

\section{Theoretical Background}

Through intensifying globalisation and arising global networks, new social and environmental challenges jeopardize innovation and growth opportunities in different markets. Indeed, this is especially true for the SME sector and the performance of individual regions in the EU (Prause et al., 2018). According to European Commission (2018a), more than $99 \%$ of all companies in the EU represent micro and SMEs. In 2015, nearly 23 million SMEs generated about 3.9 trillion EUR in value added and are responsible for approx. 90 million jobs, which mirrors an essential source of entrepreneurial spirit and innovation that is essential for the competitiveness of the EU. Therefore, SMEs are regarded as the backbone and driver of regional and national economies. Thus, there is a need to support SMEs and entrepreneurship, since they have a crucial role in generating economic growth, triggering innovations, attracting new investments and businesses, enabling clusters to evolve, ensuring employability and social integration (Dutta et al., 2018; Prause et al., 2018; EC, 2013a, 2013b, 2017; Eurostat, 2018). Hence, also in the EU Strategy of the BSR, SMEs are considered as accelerators for innovative products and services of high quality (EC, 2018b).

In the globalized knowledge society, prosperity and competitiveness of regions depend on local strengths and innovation power of local economies. Accordingly, future success will be given to companies and urban or rural regions that are able to reach global standards and join global networks as well as markets. Regional development is an innovation process, which fundamentally depends on interactions. Interaction is the source for acquiring innovation and knowledge and thus, for the economic growth and sustainable development of regions (Goddard, 1997).

The well-known cluster concept of Michael E. Porter highlights the regional aspect of a cluster by defining it as "a geographically proximate group of interconnected companies and associated institutions in a particular field, linked by commonalities and complementarities" (Porter, 2000). Accordingly, the performance and competitiveness of a cluster depends on its internal characteristics - commonalities and complementarities. Thereby, the majority of the related literature on cluster theory highlights the inherent spatial aspect of clusters by explaining why a group of companies emerge in a particular place and why they are bound to this specific place. Next to this, its external environment determines a cluster. One of most important reasons for the development of a cluster is that companies in a cluster are more productive and innovative compared to the situation of isolation. With other words, the cluster approach give competitive advantage, because it decreases the entry barriers for new business creation relative to other sites (zu Köcker, 2009). By focalising on regional innovation and networking, Goddard proposed the idea of regional knowledge or innovation networks where only those firms will be successful in a globalized economy that fulfil global standards, enter global networks and develop operational models that adapt quickly to changing market conditions and trends (Goddard, 1997 \& 2000). Hence, collaborative innovation activities of SMEs with other companies and stakeholders represent key success factors to compete in the global economy, where cluster and network initiatives form the ground base. Keeping this in mind, it can be stated that the EU-project INTERMARE South Baltic is on the right track, since it aims to support the maritime economy in the SBSR by the creation of a network of companies and stakeholders under the common brand "INTERARE South Baltic", which will be easily recognised in the region and in other European and global markets.

\section{Method}

\subsection{Data collection}

Empirical data collection activities were conducted between the $12^{\text {th }}$ of November 2018 and $11^{\text {th }}$ of June 2019, which represents a total data collection duration of about 7 month. The main target group were SMEs from the maritime sector that are located in SBSR. Accordingly, next to defined SMEs, this includes as well start-ups and micro firms, whereby all of these relevant companies must be attributable to the maritime economy in SBSR. Nevertheless, from the empirical data collection activities large 
companies were not precluded, since the objective of the present investigation is to "analyse the future potential of the maritime economy in SBSR", which implies that the maritime economy as a whole will be analysed - which vice versa leads to the inclusion of larger companies next to SMEs. The geographical scope of the empirical data collection activities is framed through all adjacent SBSR countries, namely Germany, Lithuania, Poland, Denmark and Sweden.

In order to define the maritime economy more detailed, on the basis of the elaborated findings of the preceding desk research, the decision was made to differentiate the maritime economy according to the Blue Growth Strategy of the EU. According to this definition, the Blue Economy consist of the following nine sub-sectors (EC, 2014):

- Aquaculture;

- Biotechnology;

- Coastal and maritime tourism;

- $\quad$ Fishery;

- Mineral resources;

- Offshore oil and gas;

- Renewable energy;

- $\quad$ Shipbuilding and ship repair;

- Transport (cargo / ferry).

In general, the European Commission in its Blue Growth Strategy differentiates the Blue Economy according to five focus sectors only - Renewable energy, Biotechnology, Coastal and maritime tourism, Aquaculture, Mineral resources - and mentions the other four above listed fields - Shipbuilding and ship repair, Transport, Fishery, Offshore oil and gas - as "other sectors" of the Blue Economy, since they are also crucial for value and job generation. Accordingly, this present research study follows a more detailed and profound definition of the Blue Economy by taking all nine sub-sectors into account. In contrast to this, the European Commission further refers in the context of the Blue Growth Strategy to so-called "essential components" in order "to provide knowledge, legal certainty and security in the blue economy", which directly concerns to "marine knowledge", "maritime spatial planning" and "integrated maritime surveillance" (EC, 2019). Since, firstly, these "essential components" represent in most cases non-profit orientated or stateowned and -governed/run institutions (like: universities, maritime schools, customs, water police, etc.) and, secondly, the main target group for the underlying research mainly refers to profit- and market-orientated firms, these particular fields had been excluded from the present investigation. Otherwise, the problem of differentiation between profit-orientated or market-orientated firms and non-profit orientated organisations would cause and call for further limitations. However, through the limitation of and focus on these nine subsectors, a more sharpened and clear differentiation is ensured. Furthermore, the inclusion of these three "essential components" to the scope of the defined target group would not match the overall objective of the present investigation: identification and analysis of the future potential of the maritime economy in SBSR in relation with the demand from other markets outside the region.

On the basis of this envisaged objective and building upon on the findings, which had been elaborated from a preceding desk research, a survey was elaborated. Accordingly, the objective of the survey "Future Potential of Maritime Economy in South Baltic Sea Region" was to identify and analyse the future potential of - as well as trends that currently or in the near future affect - the Blue Economy in SBSR. Thereby, it needs to be noted, that the survey developed for this purpose was based on the premise that the analysis is carried out in the SBSR, but in relation with the demand outside the region. Therefore, all in all, the related data collection activities mainly targeted to generate primary data.

In the frame of the pre-test, 31 participants from Germany, Lithuania, Estonia, Poland, Sweden and Denmark were involved. The pre-test of the online survey was conducted to establish content validity from both INTERMARE South Baltic project partners (PPs) as well as market actors. Furthermore, the major focus of the pre-test was to guarantee clarity, value as well as importance of the survey items. In addition, the pre-test procedure ensured (1) supplementation of aspects that so far have been neglected, (2) verification of the comprehensibility of questions, (3) improvement of the survey regarding structure and design, as well as (4) determination of the needed average time for survey completion (Kromrey, 2013; O'Leary, 2017; Rüdiger et al., 2011).

Hence, the empirical data collection was initially exclusively online-based, whereby the access to the online survey was provided via a specific link to the website. The invitation to the online survey reached the target group via E-Mails, which was ensured by the support of two previously selected PPs. By doing so, the following key advantages could be perceived through the online-based data collection: (1) ensuring that the survey was carried out anonymously, (2) exclusion of influencing the respondents due to the survey situation, (3) facilitation of respondents' time-based flexibility, and (4) generation of an 
adequate sample (Döring \& Bortz, 2016; Diekmann, 2007; O'Leary, 2017; Schnell et al., 2004). Possible disadvantages of the online-based survey could be reduced or eliminated. For instance, in order to prevent misuse in the form of a multiple participation, the inclusion of cookies was conducted (Schnell et al., 2004). Furthermore, comprehension problems - which can be clarified for example in an oral or telephone survey - could be largely ruled out, since the topic and its essential contents were explained at the beginning of the survey. On the other hand, this issue was also tackled by the circumstance that the previous identification of potential participants was individual performed by each PP according to the definition of the target group. Against this background, it can be assumed that the participants in the survey are familiar with the topic (Philipp et. al., 2019a).

At the end of the data collection phase, in order to achieve an adequate response rate in some target countries, companies were contacted additionally via telephone, during face-to-face meetings, training events or conferences. However, the data collection process was anonymised, and no one else with exception of the representatives of the EU-project INTERMARE South Baltic - could see the answers or information that had been provided by the participants. Furthermore, the participants of the online survey were informed on the first page of the online survey about the topic, aim and purpose of the survey and the EU-project INTERMARE South Baltic, as well as data processing. In addition, the participants had been informed that participation is voluntary. Moreover, it was indicated that the provided data was always treated confidentially and for further purposes aggregated anonymously in order to make the data usable for research and scientific purposes only. In sum, these and further given information resulted in the option for the participants to agree on the indicated consent form and provided information, or not. All these explanations and the declaration of consent were highlighted and implemented in order to be in line and to show compliance with the current EU data protection legislation (ibid.).

\subsection{Data analysis}

After successful data collection phase, seamlessly, data analysis measures were performed. The empirical data analysis activities were finished by the middle of June 2019. Instruments that had been used in the frame of the data analysis in this present study embrace mainly descriptive statistical data analysis that had been applied on the basis of the received quantitative data. In the course of descriptive statistical analysis, primary the location parameter arithmetic mean was used. In addition, the future market potential analysis was performed through the usage of the "Compound Annual Growth Rate (CAGR)" in order to measure the future growth potential of the Blue Economy in SBSR in relation with demand outside this region. The CAGR was chosen, since this key performance indicator represents an essential figure for the consideration of investments, market developments, sales, etc. in business administration as well as economics. The CAGR constitute the average annual growth of a given variable, here: turnover. The formula for the calculation of the CAGR has the following form:

$\operatorname{CAGR}\left(t_{0}, t_{n}\right)=\left(\frac{V\left(t_{n}\right)}{V\left(t_{0}\right)}\right)^{\frac{1}{t_{n}-t_{0}}}-1$,

where

CAGR Compound Annual Growth Rate;

$V\left(t_{0}\right) \quad$ Initial value;

$V\left(t_{n}\right) \quad$ End value;

$t_{n}-t_{0}$ Number of years.

\subsection{Sample description}

During the data collection phase, 362 companies accessed the online survey via the link to the website. Thereby, 362 represents only the number of companies that have accessed the online survey, even more had been contacted. However, a total of 133 companies have fully participated in the underlying survey. ${ }^{1}$ The population is made up of companies that are active in the maritime sector according to the defined target group: Blue Economy - and are located in the eligible catchment area of the "INTERREG South Baltic Programme (2014-2020)", which is further differentiated by the five eligible regions/countries: Germany, Lithuania, Poland, Denmark and Sweden. The description of the underlying sample is given in Table 1. According to Table 1, the sample size of 133 companies consist of 36 firms from Germany, 28 participants from Lithuania, 27 companies from Poland, 23 firms from

\footnotetext{
${ }^{1}$ This represents a dropout rate of $63.26 \%$.
} 
Denmark and 19 participants from Sweden. Through the comparison of the different nine sub-sectors, it is noticeable that both the sub-sectors "Transport" $(42.105 \%)$ as well as "Shipbuilding and ship repair" $(26.316 \%)$ are overrepresented in the overall sample.

Table 1. Sample description

\begin{tabular}{|c|c|c|c|c|c|c|c|c|c|c|c|c|}
\hline & \multicolumn{2}{|c|}{ SBSR } & \multicolumn{2}{|c|}{ Germany } & \multicolumn{2}{|c|}{ Lithuania } & \multicolumn{2}{|c|}{ Poland } & \multicolumn{2}{|c|}{ Denmark } & \multicolumn{2}{|c|}{ Sweden } \\
\hline & hi & fi, $\%$ & hi & fi, \% & hi & $\mathrm{fi}, \%$ & hi & fi, \% & hi & fi, \% & hi & fi, \% \\
\hline $\begin{array}{l}\text { Number/proportion } \\
\text { of participants }\end{array}$ & 133 & 100.000 & 36 & 100.000 & 28 & 100.000 & 27 & 100.000 & 23 & 100.000 & 19 & 100.000 \\
\hline \multicolumn{13}{|l|}{ Maritime sector } \\
\hline Aquaculture & 8 & 6.015 & 4 & 11.111 & 1 & 3.571 & 3 & 11.111 & 0 & 0.000 & 0 & 0.000 \\
\hline Biotechnology & 6 & 4.511 & 1 & 2.778 & 1 & 3.571 & 4 & 14.815 & 0 & 0.000 & 0 & 0.000 \\
\hline $\begin{array}{l}\text { Coastal \& } \\
\text { maritime tourism }\end{array}$ & 10 & 7.519 & 3 & 8.333 & 2 & 7.143 & 1 & 3.704 & 3 & 13.043 & 1 & 5.263 \\
\hline Fishery & 6 & 4.511 & 4 & 11.111 & 2 & 7.143 & 0 & 0.000 & 0 & 0.000 & 0 & 0.000 \\
\hline Mineral resources & 3 & 2.256 & 2 & 5.556 & 1 & 3.571 & 0 & 0.000 & 0 & 0.000 & 0 & 0.000 \\
\hline Offshore oil \& gas & 2 & 1.504 & 0 & 0.000 & 1 & 3.571 & 0 & 0.000 & 1 & 4.348 & 0 & 0.000 \\
\hline Renewable energy & 7 & 5.263 & 2 & 5.556 & 2 & 7.143 & 2 & 7.407 & 1 & 4.348 & 0 & 0.000 \\
\hline $\begin{array}{ll}\text { Shipbuilding } \\
\text { ship repair }\end{array}$ & 35 & 26.316 & 11 & 30.556 & 3 & 10.714 & 10 & 37.037 & 5 & 21.739 & 6 & 31.579 \\
\hline $\begin{array}{l}\text { Transport } \\
\text { (cargo/ferry) }\end{array}$ & 56 & 42.105 & 9 & 25.000 & 15 & 53.571 & 7 & 25.926 & 13 & 56.522 & 12 & 63.158 \\
\hline \multicolumn{13}{|l|}{ Company size } \\
\hline Micro & 33 & 24.812 & 6 & 16.667 & 11 & 39.286 & 14 & 51.852 & 1 & 4.348 & 1 & 5.263 \\
\hline Small & 33 & 24.812 & 9 & 25.000 & 9 & 32.143 & 9 & 33.333 & 5 & 21.739 & 1 & 5.263 \\
\hline Medium & 55 & 41.353 & 18 & 50.000 & 4 & 14.286 & 4 & 14.815 & 15 & 65.217 & 14 & 73.684 \\
\hline Large & 12 & 9.023 & 3 & 8.333 & 4 & 14.286 & 0 & 0.000 & 2 & 8.696 & 3 & 15.789 \\
\hline \multicolumn{13}{|l|}{ Year of foundation } \\
\hline before 2004 & 98 & 73.684 & 31 & 86.111 & 17 & 60.714 & 11 & 40.741 & 22 & 95.652 & 17 & 89.474 \\
\hline $2004-2008$ & 9 & 6.767 & 2 & 5.556 & 2 & 7.143 & 3 & 11.111 & 0 & 0.000 & 2 & 10.526 \\
\hline $2009-2013$ & 8 & 6.015 & 2 & 5.556 & 3 & 10.714 & 2 & 7.407 & 1 & 4.348 & 0 & 0.000 \\
\hline $2014-2018$ & 18 & 13.534 & 1 & 2.778 & 6 & 21.429 & 11 & 40.741 & 0 & 0.000 & 0 & 0.000 \\
\hline
\end{tabular}

\section{Findings}

\subsection{Future potential}

In order to identify the future potential of the maritime economy in SBSR, in the underlying online survey, participants that represent the Blue Economy of SBSR - according to the defined target group had been asked to estimate their company's turnover growth rate (in \%) for the next five years (2019 to 2023) according to different geographical markets: Regional, National, BSR, Europe, Africa, Asia, Australia, North America and South America. This was done, since the objective was to carry out the investigation in SBSR, but in relation with the demand outside the region. Therefore, the nine examined markets are separated in domestic markets (incl. Regional, National, BSR) and international markets (incl. Europe, Africa, Asia, Australia, North America, South America), whereby the latter case encapsulates the demand outside the SBSR.

In the frame of the BSR as a market, the decision was made to incorporated this specific market in the category of domestic markets, since from the perspective of the maritime economy in SBSR, the BSR mainly represents to a large extend the home market. Another potential overlap exist in the course of the analysed European market, since the European market incorporates also the BSR market. However, the BSR market represents only a small part of the entire European market, and thus, the European market was logically included in the category of international markets. Through the aggregation of the received data in case of the six continental markets (i.e. Europe, Africa, Asia, Australia, North America, South America), it became possible to derive conclusions about the holistic worldwide demand that is attributable to the maritime economy of SBSR.

Moreover, it should be noted that in the following, firstly, the received results are presented in relation to country differentiation/affiliation (incl. all participating countries that belong to the eligible area of the "INTERREG South Baltic Programme": Germany, Lithuania, Poland, Denmark and Sweden), and afterwards, in contrast to the differentiation of the respective nine sub-sectors (i.e. Aquaculture, Biotechnology, Coastal and maritime tourism, Fishery, Mineral resources, Offshore oil and gas, Renewable energy, Shipbuilding and ship repair, Transport) of the Blue Economy. Accordingly, through the aggregation of the received results of all five countries (Germany, Lithuania, Poland, Denmark and 
Sweden), the holistic perspective of the maritime economy from SBSR as a whole is gathered, which is equal to the aggregation of the received results of all investigated nine sub-sectors (Aquaculture, Biotechnology, Coastal and maritime tourism, Fishery, Mineral resources, Offshore oil and gas, Renewable energy, Shipbuilding and ship repair, Transport). Thus, on the one hand, the aggregation of the received results from national level, and on the other hand, the aggregation of received results from sub-sector level, form the study sample: maritime economy in SBSR - neglecting the circumstance that in the following in some cases only the SBSR or maritime economy alone is showcased.

The duration of five years (2019 to 2023) was chosen, since longer periods are often associated with higher uncertainties. Accordingly, in order to have more reliable results, the duration of five years was set, which further fosters the trust in the following concluding remarks. On the other hand, through this, urgent and rapid need for actions are better identifiable.

The received data through the online survey in form of estimated company's turnover growth rate (in \%) for the next five years (2019 to 2023) was processed through descriptive statistical analysis by using the arithmetic mean. Thereby, turnover growth rates over $20 \%$ and under $-20 \%$ had been considered as outliers and therefore, had been excluded from further analysis. In this context, it should be noted that in the survey, no participating company estimated a growth rate of less than $-20 \%$. Only in some cases, very optimistic estimations with more than $20 \%$ had been indicated by some firms $(\mathrm{hi}=7)$. Deeply rooted in the fact that these too optimistic answers had been considered as outliers, it can be stated that the overall analysis of the future potential of the maritime economy in SBSR follows rather a pessimistic perspective, which means that the gained results are closer to more realistic market conditions. Since the received arithmetic mean values refer to the expected total growth rates of the entire period of five years (2019 and 2023), the CAGR was calculated and further used for interpretations. Accordingly, in this study, for the analysis of the future potential of the maritime economy in SBSR, the CAGR is used as the representative indicator.

\section{Domestic markets}

The elaborated results for the domestic markets differentiated according to the five nations of the SBSR are summarised in Figure 1. According to Figure 1, from a holistic perspective (i.e. maritime economy from SBSR as a whole), the national markets (1.274\%) and the entire BSR market (1.213\%) are associated with the highest turnover growth rates, since the CAGR for the regional markets in the near proximity of the Blue Economy firms is a little bit lower with $1.178 \%$, but still can be evaluated as moderate. Therefore, it can be stated that especially the domestic markets play a crucial role in the future for maritime economy companies from the SBSR, based on aggregated results.

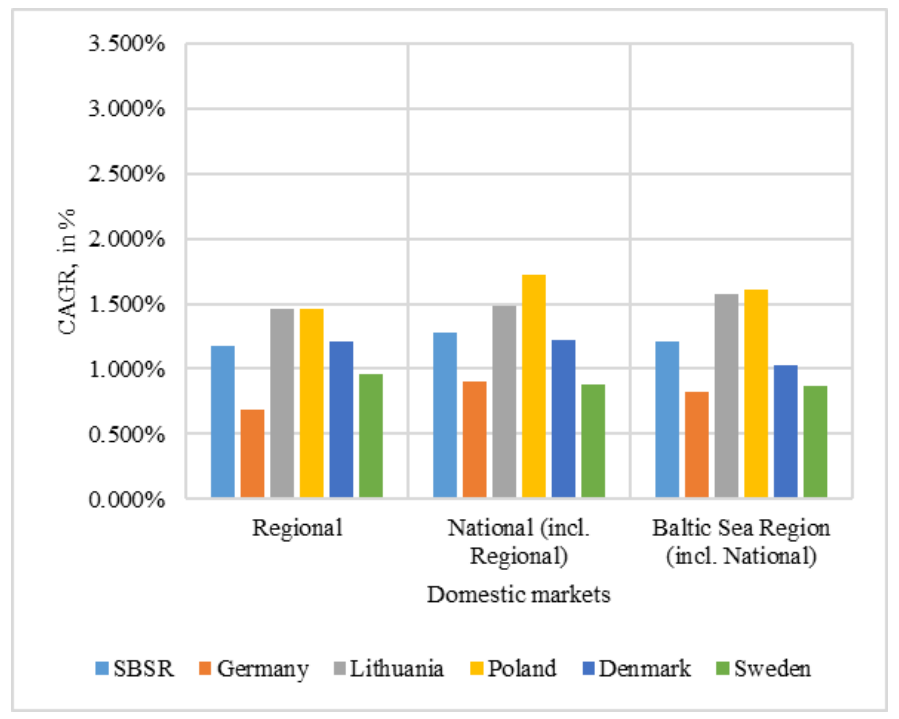

Figure 1. CAGR on national level - domestic markets

By having a closer look on the results on respective national level, it becomes obvious that Swedish and especially German companies of the maritime economy, evaluate the annual turnover growth rates (CAGRs) on all three differentiated domestic markets (i.e. Regional, National, BSR) rather pessimistic $(\mathrm{SE}$ : Regional $=0.957 \%$, National $=0.884 \%$, BSR $=0.865 \% ;$ DE: Regional $=0.681 \%$, 
National $=0.899 \%$, BSR $=0.822 \%$ ), compared to the Blue Economy firms from Lithuania and Poland $(\mathrm{LT}:$ Regional $=1.466 \%$, National $=1.479 \%, \mathrm{BSR}=1.579 \% ;$ PL: Regional $=1.466 \%$, National $=1.722 \%$, $\mathrm{BSR}=1.61 \%$ ), whereby the obtained respective values from Danish firms lay in the middle (Regional = $1.215 \%$, National $=1.217 \%, \mathrm{BSR}=1.026 \%$ ). Especially, the CAGR that refers to maritime economy firms from Germany in relation to the regional markets $(0.681 \%)$ can be evaluated as too low. Against this, the CAGRs of Lithuania and Polish Blue Economy companies with an average of 1.5\% (or more) reveal that for these companies the domestic markets (i.e. Regional, National, BSR) are of high importance in the future. Furthermore, in case of Lithuanian maritime economy firms, it becomes obvious that that through the increase of the geographical scope of the market, the CAGR increases as well, whereby vice versa, in the case of Swedish Blue Economy firms with an increase of the geographical scope of the market, the CAGR decreases.

The results for the domestic markets differentiated according to the nine sub-sectors of the Blue Economy are summarised in Figure 2. According to Figure 2, it can be concluded that the importance of the three different domestic markets among the nine sub-sectors of the Blue Economy is quite unbalanced. For instance, for the maritime economy sub-sector Aquaculture, a moderate CAGR on the national markets $(1.199 \%)$ and to a certain extent on the BSR market (1.029\%) was calculable, whereby the regional markets for Aquaculture companies from the SBSR are associated with a low future potential, since the expected annual growth rate with $0.852 \%$ is quite low. Similarities are visible for the sub-sector Coastal \& maritime tourism, since the CAGR in case of the national markets represents only $0.787 \%$, whereby a moderate level of the CAGRs was detected for the BSR market (1.013\%), and to a certain extent for the regional markets $(0.953 \%)$. Even more dramatic are the findings that are related to the sub-sector Mineral resources, since all predicted CAGRs for the three domestic markets are under $0.8 \%$ (Regional $=0.787 \%$, National $=0.69 \%, \mathrm{BSR}=1.362 \%$ ) - whereby obviously through the increase of the geographical scope of the market, the CAGR decreases, too. Also for the sub-sector Renewable energy, the CARGs that refer to the regional $(0.884 \%)$ and national markets $(0.916 \%)$ cannot convince; only for the BSR market (1.21\%), the annual turnover growth rate (CAGR) promise acceptable moderate growth in the near future - whereby obviously through the increase of the geographical scope of the market, the CAGR increases as well. Slightly better, but also a little bit similar, are the findings that refer to the sub-sector Transport, since the estimated CARGs for the three domestic markets are on a moderate level between $1.074 \%$ (Regional) and $1.153 \%$ (BSR), or $1.084 \%$ for the national markets, respectively whereby again obviously through the increase of the geographical scope of the market, the CAGR increases, too. Therefore, it can be stated and concluded that for all these sub-sectors - namely: Aquaculture, Coastal \& maritime tourism, Mineral resources, Renewable energy and Transport - the domestic markets show only a low or in some cases moderate future growth potential.

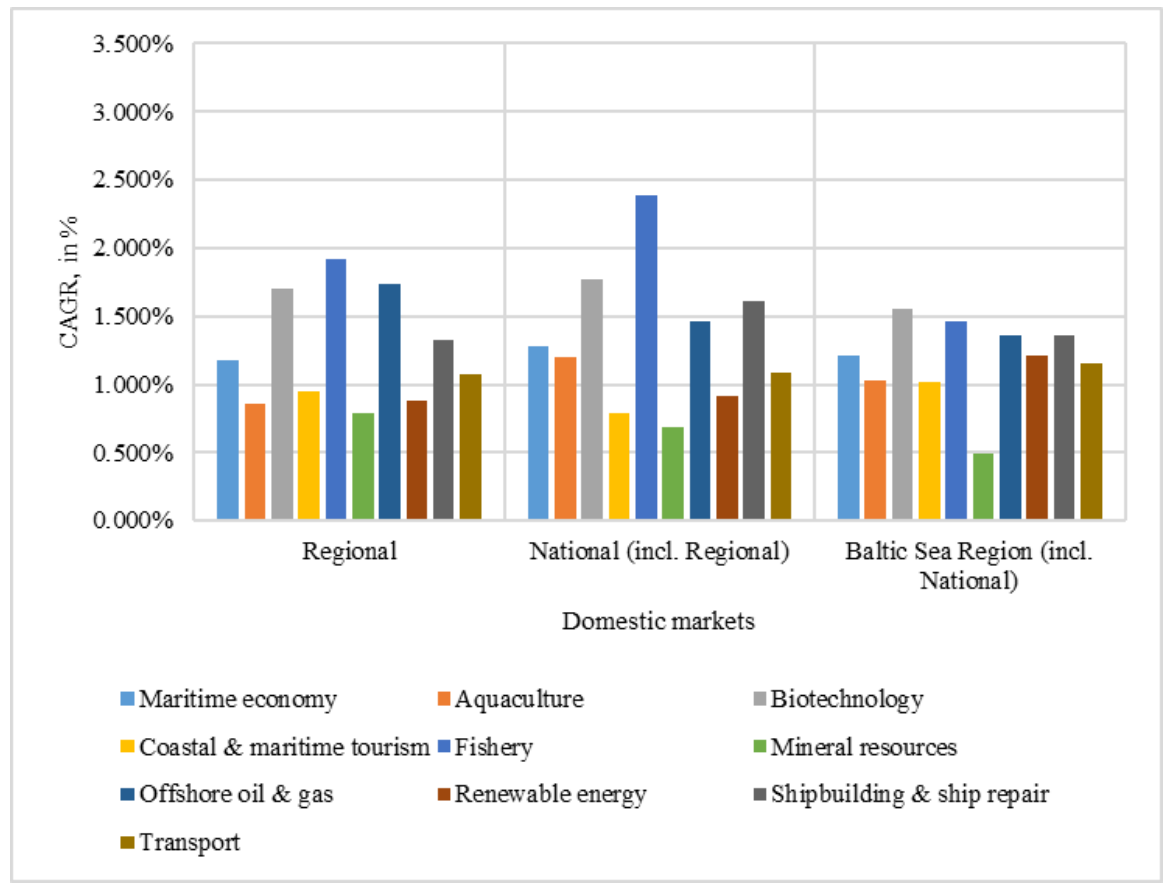

Figure 2. CAGR on Blue Economy sector level - domestic markets 
All other four sub-sectors - namely: Biotechnology, Fishery, Offshore oil \& gas, Shipbuilding \& ship repair - exhibit greater future growth potentials on the domestic markets. For instance the average CAGR for Biotechnology firms on the basis of all three domestic markets is equal to $1.676 \%$ (Regional = $1.707 \%$, National $=1.770 \%, \mathrm{BSR}=1.551 \%$ ). Even greater is the future growth potential on the domestic markets that is related to the sub-sector Fishery, since the CARG for the regional markets is equal to $1.924 \%$, for the national markets $2.384 \%$ - which is one of the highest CAGRs in the entire present study - and $1.457 \%$ for the BSR market. Also the Offshore oil \& gas sector promises a sufficient growth potential in the next years on the domestic markets - Regional $=1.738 \%$, National $=1.457 \%$ and $\mathrm{BSR}=$ $1.362 \%$ - whereby obviously through the increase of the geographical scope of the market, the CAGR decreases, too. On a similar attractive level are the predicted CARGs for the three domestic markets that occur in case of the sub-sector Shipbuilding \& ship repair, with $1.324 \%$ on the regional, $1.611 \%$ on the national, and $1.354 \%$ on the BSR market(s).

\section{International markets}

The elaborated results for the international markets differentiated according to the five nations of the SBSR are summarised in Figure 3. According to Figure 3, from a holistic perspective (i.e. maritime economy from SBSR as a whole), among all continental markets the European market $(1.332 \%)$ represents the most important one, since the highest CAGR is expected, which suggest even greater future growth potential than the different domestic markets. Furthermore, also the Asian market exhibits some relevance with an annual turnover growth rate of $0.981 \%$. Vice versa, all other continental markets (Africa $=0.674 \%$, Australia $=0.620$, North America $=0.778 \%$ and South America $=0.758 \%$ ) show a very low future growth potential. This might be seen as an indicator that overall there is very low demand on these international markets for products and services that are offered by maritime companies from SBSR. On the other hand, another explanation might be seen in the possibility that maritime companies from SBSR are not active enough on these international markets due to their general low degree of internationalisation. Lastly, the aggregated results of all international markets resulted in the achieved CARG worldwide, which is only about $0.955 \%$. Hence, it can be concluded that generally the future potential of the maritime economy from SBSR on international markets is nearly moderate, but not very attractive. Furthermore, it can be stated that from a holistic perspective, especially the European market plays a crucial role in the future for maritime economy companies from SBSR.

As mentioned before, Swedish and especially German Blue Economy firms evaluate the future growth potential on domestic markets more pessimistic than companies from other SBSR countries. The same applies for the international markets (SE: Europe $=0.9 \%$, Africa $=0.981 \%$, Asia $=0.884 \%$, Australia $=0 \%$, North America $=0.397 \%$, South America $=1.172 \%$, Worldwide $=0.815 \%$; DE: Europe $=0.862 \%$, Africa $=0.232 \%$, Asia $=0.475 \%$, Australia $=0.232 \%$, North America $=0.159 \%$, South America $=0.080 \%$, Worldwide $=0.441 \%$ ). An exception is the market in South America for maritime economy companies from Sweden, since among all compared markets (incl. domestic markets) the highest growth potential is predicted for the South American market (1.172\%) in case of Swedish firms. Nevertheless, this finding can be evaluated only as moderate. In addition, it can be derived that among all partial samples, Blue economy firms from Sweden exhibit the highest CAGR for the African market $(0.981 \%)$. Against this, especially the Australian markets has no relevance for firms from Sweden $(0 \%)$ and the resulting worldwide CAGR with $0.815 \%$ is also quite low. In case of the German firms, all CARGs on international markets are too low, whereby compared with the values that had been achieved on the domestic markets, it can be stated that the European market has a similar relevance $(0.862 \%)$, which at the same time is the highest CARG of all international markets in case of German firms. In contrast to the Swedish companies, for German firms, the market in South America has no relevance due to a CAGR of $0.080 \%$. Therefore, the resulting annual growth rate worldwide with $0.441 \%$ in case of German Blue Economy firms is insufficient.

Against this, the maritime economy firms from Denmark show high future potential among all international markets $($ Asia $=2.565 \%$, Australia $=3.19 \%$, North America $=1.645 \%$, South America $=$ $1.513 \%$, Worldwide $=1.47 \%$ ), whereby for the African market no data was received, and the CARG that refers to the European market $(1.16 \%)$ can be evaluated as on a moderate level, similar as the other domestic markets. The CARGs for Asia, Australia, North America and South America by Danish firms, represent the highest growth potential on international markets in the next years among all SBSR countries, whereat also in the case of the worldwide CARG Danish companies are outperforming.

For both, Lithuanian (1.636\%) and Polish (1.738\%) firms, among all international markets, the European market is the most important one. Additionally, in case of maritime economy companies from Lithuania, also the Asian market $(1.213 \%)$ has a moderate priority, as well as to a certain degree also the 
market in South America (0.965\%), whereby in case of Polish companies, only the North American $(0.965 \%)$ market has some additional relevance. Accordingly, it can be concluded that for Lithuanian firms, the business in African (0.906\%), Australian (0.928\%) and North American $(0.671 \%)$ markets is not attractive. Even worse is the predicted future growth potential of Polish companies on the African $(0.593 \%)$, Asian $(0.658 \%)$, Australian $(0.298 \%)$ and South American $(0.331 \%)$ markets. The overall worldwide CAGR in case of Lithuanian companies $(1.1 \%)$ can be assessed as moderate, whereby the aggregated worldwide annual growth rate in the course of Polish firms $(0.905 \%)$ is too low.

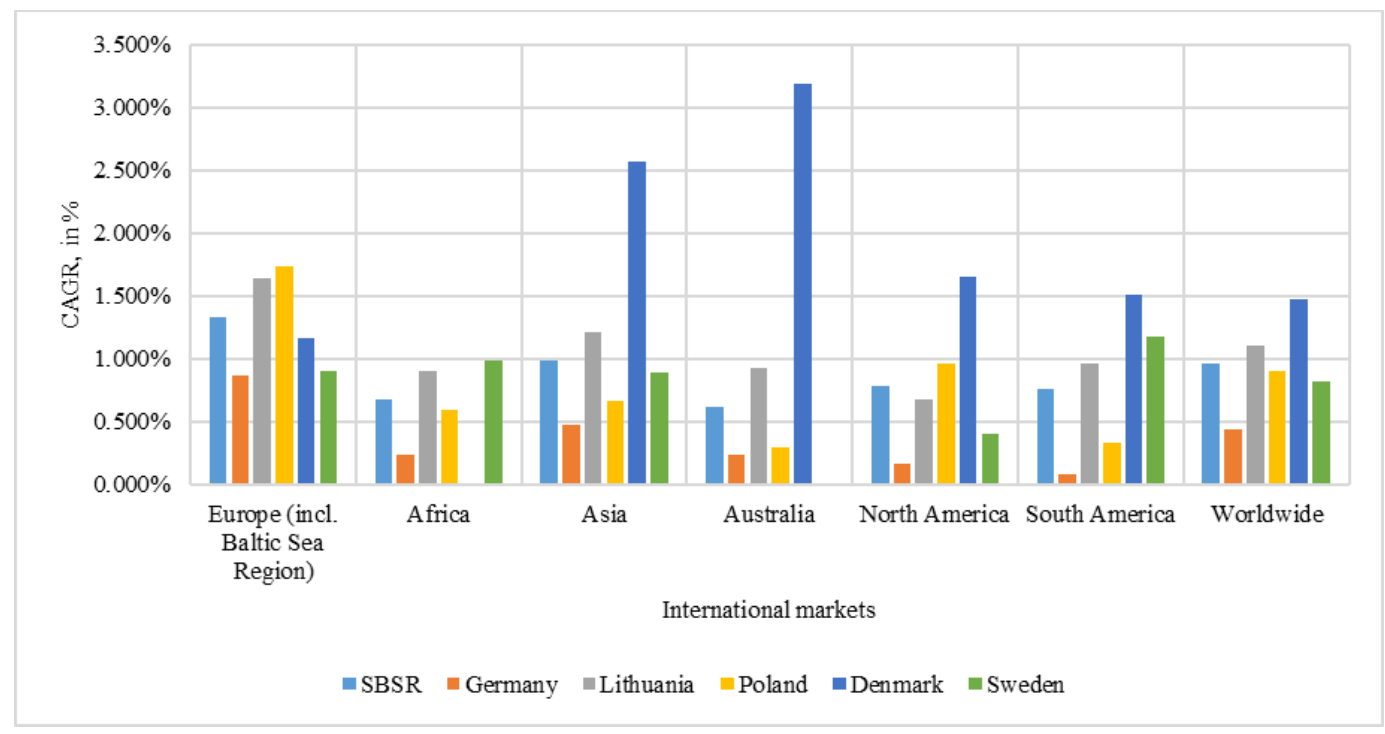

Figure 3. CAGR on national level - international markets

The results for the international markets differentiated according to the nine sub-sectors of the Blue Economy are summarised in Figure 4 below. According to Figure 4, it can be concluded that the importance of the international markets among the nine sub-sectors of the Blue Economy is quite heterogenic. For instance, for the maritime economy sub-sector Aquaculture from SBSR, international continental markets play no role (Africa, Asia, Australia, North America, South America $=0 \%$ ), with a small exception in case of the European market (0.723\%), which is also still less attractive. Accordingly, also the aggregated results in form of the worldwide CAGR cannot convince $(0.273 \%)$ in case of the subsector Aquaculture. Similarities apply for the sub-sector Biotechnology, where international markets are once again unappealing (Africa $=0 \%$, Asia $=0.199 \%$, Australia $=0 \%$, North America $=0.739 \%$, South America $=0 \%)$. Single bright spot is the European market with a quite strong CAGR $(1.629 \%)$, which is on a similar level as noticed on the domestic markets, and the highest score compared to all other subsectors. Nevertheless, the overall worldwide CARG of Biotechnology firms is with $0.616 \%$ too low. Quite similar are the findings in case of the Blue Economy sub-sector Fishery (Africa, Asia, Australia = $0 \%$, North America $=0.495 \%$, South America $=0 \%$ ), whereby at least the CARG that belongs to the European market $(0.981 \%)$ can be evaluated as more or less moderate. Nevertheless, in case of the subsector Fishery, the cumulated results that form the worldwide annual growth perspective $(0.372 \%)$ are insufficient. Also for the sub-sector Mineral resources, international markets play completely no role (Europe, Africa, Asia, Australia, North America, South America, Worldwide $=0 \%$ ). To the same group of "losers" also belongs the sub-sector Offshore oil \& gas, since again, the achieved results suggest that there is no future potential for these sub-sector companies from SBSR on these respective international markets (Africa, Asia, Australia, North America, South America =0\%), whereat exception is made again in case of the European market with a positive result in terms of the CAGR (1.457\%). Therefore, it is also not surprising that the resulting worldwide CAGR $(0.425 \%)$ is also quite low in case of Offshore oil \& gas companies from SBSR. Finally, it can be concluded that for all these sub-sectors (incl. Aquaculture, Biotechnology, Fishery, Mineral resources, Offshore oil \& gas) domestic markets have a higher priority than international markets.

A little bit better is the picture in case of the maritime Transport sector, since the CAGR that refers to the European market is on a moderate level with $1.244 \%$ and in case of the Asian market $(1.013 \%)$ more or less moderate. In case of all other international markets (incl. Africa $=0.826 \%$, Australia $=0.174 \%$, North America $=0.619 \%$, South America $=0.868 \%$ ), the predicted annual turnover growth rates are 
insufficient. This is also reflected by the received worldwide CARG $(0.933 \%)$ in case of companies that belong to the maritime Transport sector.

In case of the sub-sector Coastal \& maritime tourism, moderate demand is expected from the European (1.299\%) and Asian (1.108\%) market, whereby the revenue stream from North America is the highest among all included sub-sectors (1.676\%). In contrast to this, the demand from the African $(0.298 \%)$, Australian $(0.787 \%)$ and South American $0.495 \%)$ market is very low. Nevertheless, the thereof resulting worldwide CARG in the frame of the sub-sector Coastal \& maritime tourism with $1.077 \%$ is still moderate.

In comparison to all sub-sectors of the Blue Economy from SBSR, the highest future growth rates are visible through Renewable energy companies on African (1.457\%) and Australian (1.645\%) markets. Against this, the CAGR that refers to the Asian market $(1.267 \%)$ can be assessed as moderate and in case of the North American market $(1.077 \%)$ as still moderate. Vice versa, the European $(0.787 \%)$ and South American $(0.884 \%)$ market play a subordinate role in case of Renewable energy firms. However, the resulting worldwide future annual turnover growth rate $(1.131 \%)$ of Renewable energy firms is also moderate.

Similarities apply for the sub-sector Shipbuilding \& ship repair, where the highest CARGs on the European (1.694\%) and Asian (1.414\%) markets are noticeable in the entire sample differentiated according to the different Blue Economy sectors. Also in case of the Australian (1.05\%) and South American (1.068\%) markets, the future potential can still be evaluated as moderate, whereby it is a little bit surprising and sorrowful that the CARG for South America, which was achieved by Shipbuilding \& ship repair companies, at the same time is also the highest among all other sub-sectors. Furthermore, the CARG for North America (0.981\%) shows a tendency to a moderate level. Therefore, only the annual turnover growth rate that belongs to the African market $(0.852 \%)$ can be assessed as a little bit too low. Accordingly, by taking all these detailed results into account, it is not surprising that the resulting worldwide average growth rate with $1.216 \%$ of the Shipbuilding \& ship repair sector is the greatest in the whole sample.

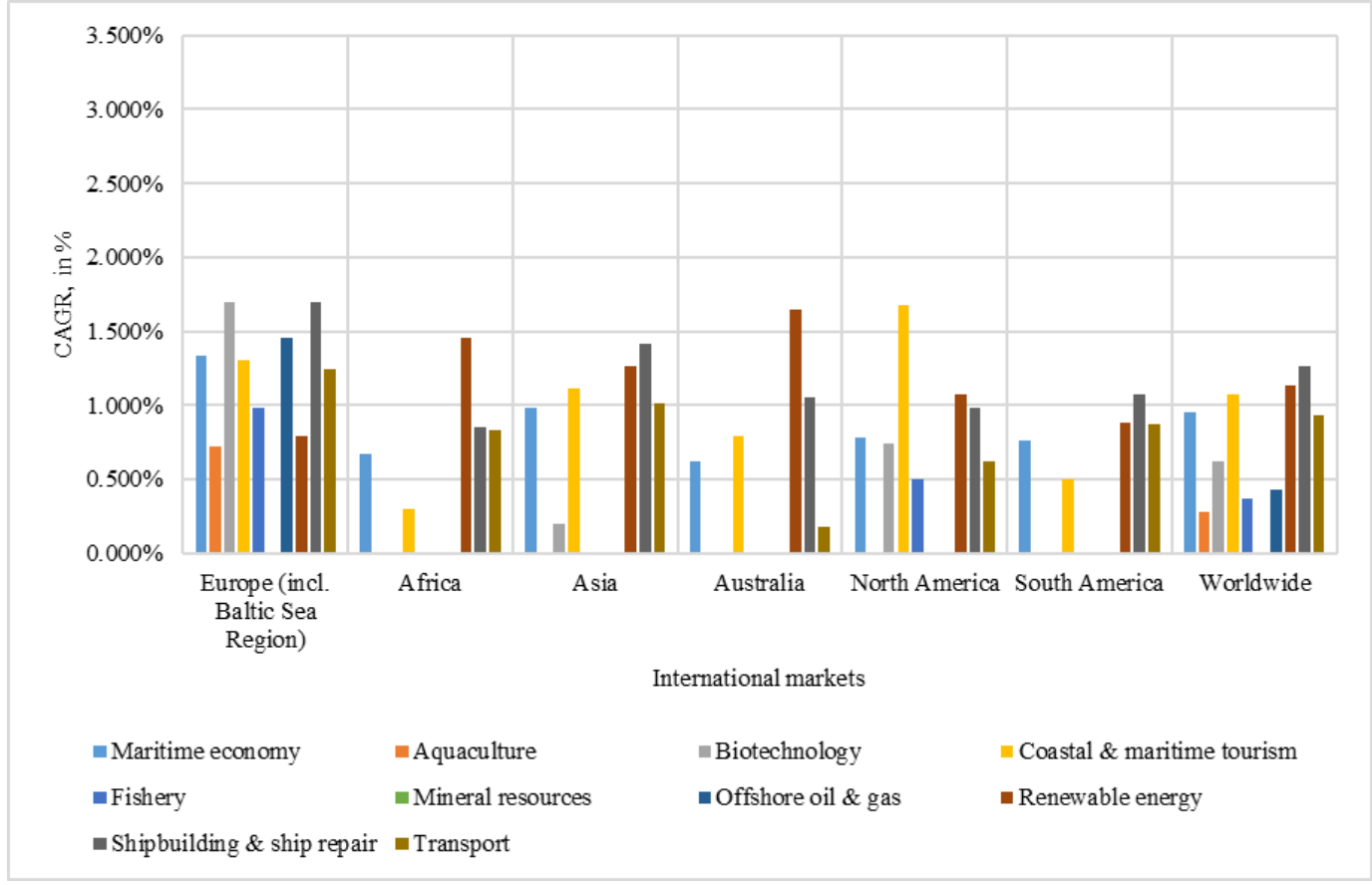

Figure 4. CAGR on Blue Economy sector level - international markets

\subsection{Trends}

In order to identify trends that have a potential influence on the future business of maritime economy companies from SBSR, in the underlying online survey, participants had been asked to evaluate the strength and the kind (i.e. positive or negative) of the impact from (1) Digitalisation, (2) European Guidelines for the development of the TEN-T and (3) International regulations that affect business of maritime industry and related stakeholders - particularly IMO Marpol Annex VI, BSR as Sulphur 
Emission Control Area (SECA); Global Sulphur Cap; etc. These potential trends were chosen for the present study, since they are currently highly discussed in the research landscape on maritime industry (e.g. Henesey \& Philipp, 2019; Madjidian et al., 2017; Meyer et al., 2020; Philipp et al., 2018, 2019b, 2019c \& 2020). By doing so, a five item scale was given with "(-2) Very negative", "(-1) Rather negative", "(0) Neutral”, “(+1) Rather positive" and "(+2) Very positive”, whereby participants also had the option to choose "Not aware", which - of course - is excluded from the following analysis. The received data through the online survey - structured according to this Likert-scale - was processed through descriptive statistical analysis by using the arithmetic mean.

Once again, it should be noted that in the following, firstly, the received results are presented in relation to country differentiation/affiliation and secondly, in contrast to the differentiation of the different nine sub-sectors of the Blue Economy. Accordingly, through the aggregation of the received results of all five countries, the holistic perspective of the maritime economy from SBSR as a whole is gathered, which is equal to the aggregation of the received results of all investigated nine sub-sectors. Thus, on the one hand, the aggregation of the received results from national level, and on the other hand, the aggregation of received results from sub-sector level, form the study sample: maritime economy in SBSR - neglecting the circumstance that in the following in some cases only the SBSR or maritime economy alone is showcased.

The elaborated results in the frame of the trend analysis differentiated according to the five nations of the SBSR are summarised in Figure 5 below. According to Figure 5, from a holistic perspective, digitalisation has the highest importance and thus, is expected to have the strongest impact on the future business of Blue economy firms from SBSR with a resulting arithmetic mean of 0.969; compared with the other considered potential trends TEN-T (0.39) and SECA Regulation \& Global Sulphur Cap (0.27). Furthermore, it should be noted that all three potential impacts show a positive sign, which indicates that all three trends are expected to have a positive impact on the future business of maritime economy companies from SBSR.

This finding is also noticeable on respective national level, where digitalisation generally is expected to have the greatest positive impacts on the future business $(\mathrm{DE}=0.889, \mathrm{LT}=0.923, \mathrm{PL}=1.12$, $\mathrm{DK}=1, \mathrm{SE}=0.947$ ). By comparing the other two trends (TEN-T and SECA Regulation \& Global Sulphur Cap), it can be stated that German, Lithuanian and Polish companies predict that the TEN-T (DE $=0.286, \mathrm{LT}=0.538, \mathrm{PL}=0.571)$ will have a greater positive influence on their future business than SECA Regulation \& Global Sulphur Cap $(\mathrm{DE}=0.176, \mathrm{LT}=0.231, \mathrm{PL}=0.238)$. Vice versa, in case of maritime economy companies from Denmark and Sweden the impact of the trend in case of SECA Regulation \& Global Sulphur Cap $(\mathrm{DK}=0.409, \mathrm{SE}=0.368)$ is higher positively evaluated than the one that will be induced by the TEN-T $(\mathrm{DK}=0.348, \mathrm{SE}=0.222)$. Nevertheless, also on individual national level, all potential trends are expected to have a positive impact on the future business.

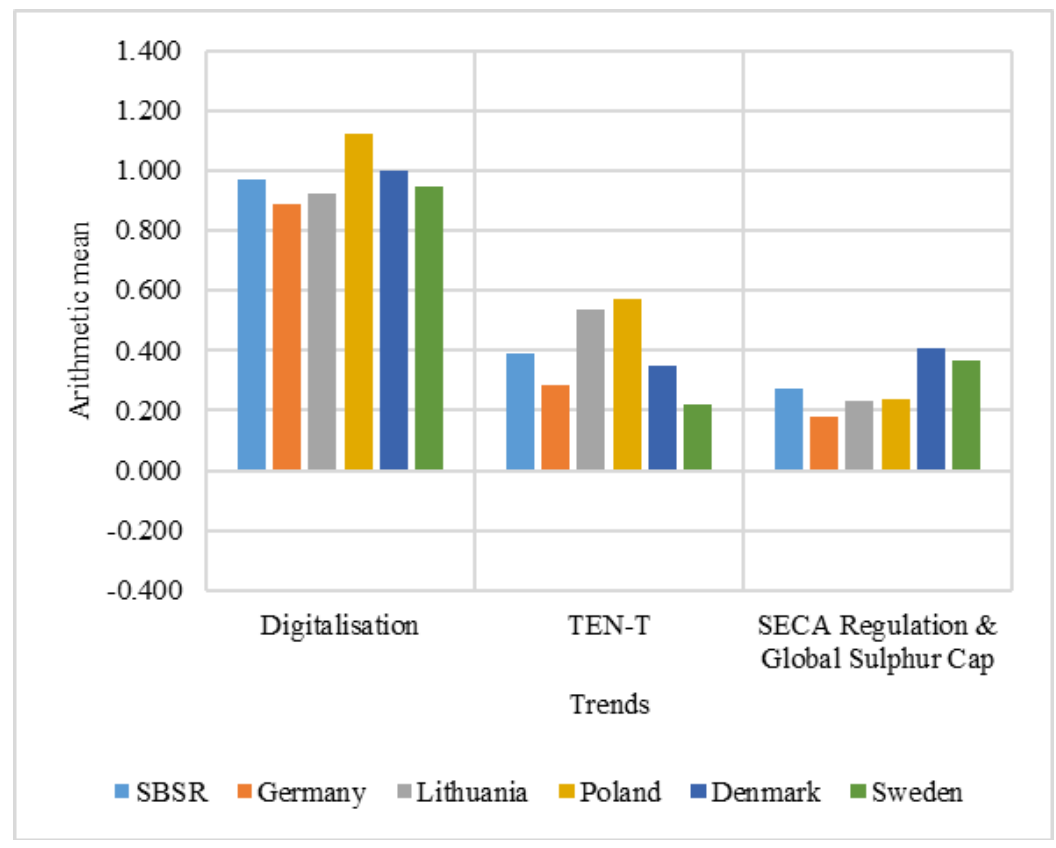

Figure 5. Trends on national level 
The results in the frame of the trend analysis differentiated according to the nine sub-sectors of the Blue Economy are summarised in Figure 6. According to Figure 6, it can be derived that also digitalisation is expected to have among all nine sub-sectors of the Blue Economy in SBSR the greatest positive impact (Aquaculture $=1.25$, Biotechnology $=0.833$, Coastal $\&$ maritime tourism $=1.1$, Fishery $=$ 0.333 , Mineral resources $=0.667$, Offshore oil \& gas $=1$, Renewable energy $=0.667$, Shipbuilding \& ship repair $=0.879$, Transport $=1.091$, whereat the expected intensity varies. Only Offshore oil $\&$ gas companies predict that the TEN-T will have the same strong positive impact as digitalisation on their future business, whereby SECA Regulation \& Global Sulphur Cap also is expected to a have a positive impact on future business activities (0.5), but not as strong as in case of digitalisation and TEN-T. Furthermore, firms from the Aquaculture sector claim that the TEN-T will have a stronger positive influence on their future business (0.429) than SECA Regulation \& Global Sulphur Cap, where no impact is expected at all. In contrast to this, Biotechnology firms predict generally no relevance of the TEN-T and SECA Regulation \& Global Sulphur Cap for their future business, neither directly nor indirectly. Coastal \& maritime tourism firms see equal strong positive influences on their business that might emerge from the TEN-T and SECA Regulation \& Global Sulphur Cap (both: 0.333). The results of the Fishery sector from the SBSR encapsulate a peculiarity, since the TEN-T is expected to have a negative influence on the future business (-0.167), whereby the arithmetic mean in case of SECA Regulation \& Global Sulphur Cap implies that this trend seem to have no future relevance. A similar peculiarity is obvious in case of the sub-sector Mineral resources, since these firms predict that SECA Regulation \& Global Sulphur Cap will have a negative impact on their future business (-0.333), but TEN-T a positive one (0.333) with the same intensity. Renewable energy firms evaluate the future business impacts coming from TEN-T (0.333) and SECA Regulation \& Global Sulphur Cap (0.167) positive, but in case of the TEN-T a little bit stronger. In the course of Shipbuilding \& ship repair companies, the influence of TEN$\mathrm{T}$ (0.452) and SECA Regulation \& Global Sulphur Cap (0.484) on the future business is expected to be positive and nearly equipollent. In contrast to this, the Transport sector predicts a stronger positive impact from the TEN-T (0.444) than from the SECA Regulation \& Global Sulphur Cap (0.259).

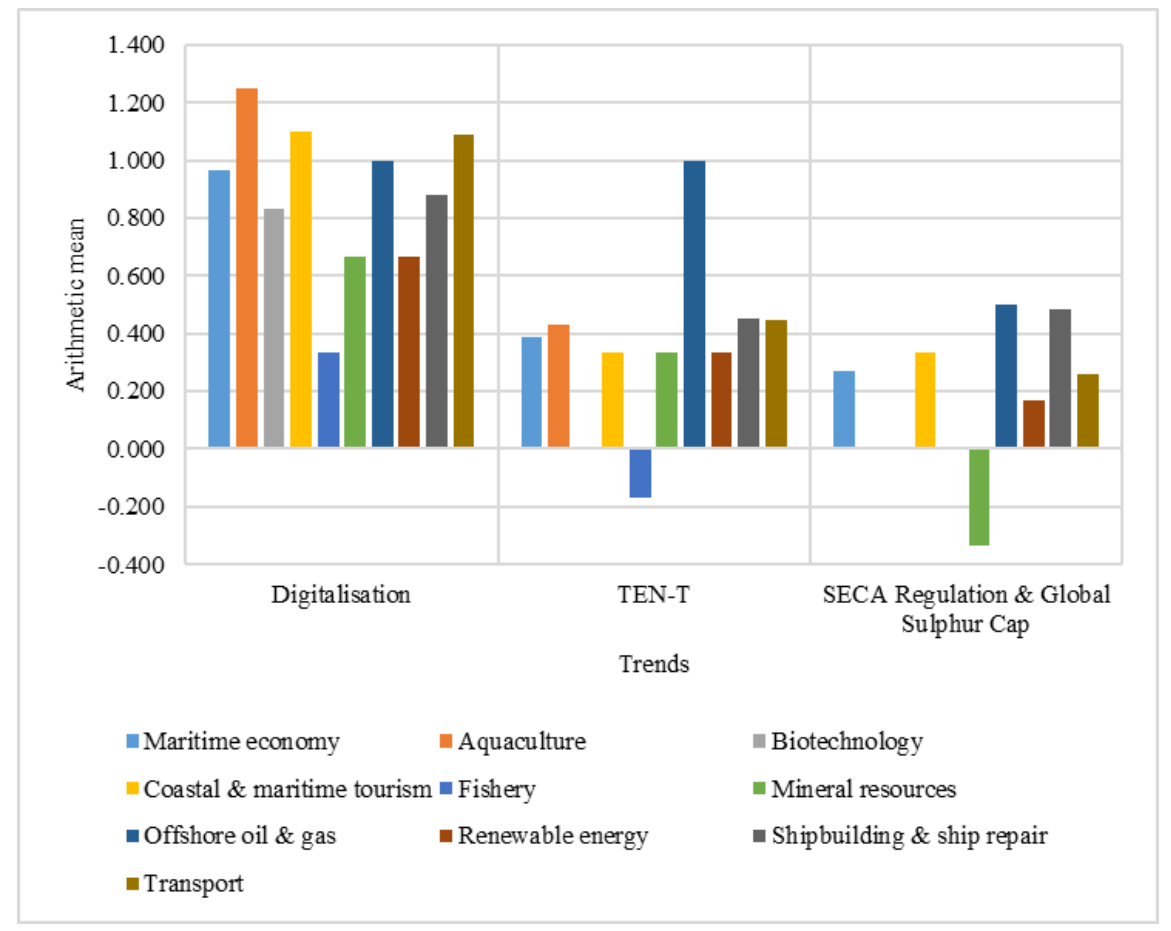

Figure 6. Trends on Blue Economy sector level

\section{Discussion and conclusion}

In this study, the future potential of the maritime economy in SBSR as well as trends that impact the future sustainable development of this blue sector were investigated. By taking all findings into account, it can be concluded that overall - from a holistic perspective on the maritime economy in SBSR - domestic markets and the European market are more important than all other international markets. In 
addition, generally, the worldwide CAGR of the entire Blue economy from SBSR is with $0.955 \%$ on a moderate level. Furthermore, the maritime economy firms from Germany and Sweden will face some disadvantages compared to companies from Lithuania, Poland and Denmark, since their expected future market potential is quite low, with exception of the South American market in case of Swedish firms. From a sector specific perspective, it can be determined that most of the sub-sectors show also low future growth potential. For instance, it can be concluded that for the sub-sectors Aquaculture, Coastal \& maritime tourism, Mineral resources, Renewable energy as well as Transport, the domestic markets have only low or in some cases moderate future growth potentials. All other four sub-sectors - namely: Biotechnology, Fishery, Offshore oil \& gas, Shipbuilding \& ship repair - exhibit greater future growth potentials on the domestic markets. Moreover, it can be derived that for the sub-sectors Aquaculture, Biotechnology, Fishery, Mineral resources as well as Offshore oil \& gas, domestic markets will have a higher priority than international markets. Thereby, especially the sub-sectors Aquaculture and Mineral resources will face some problems, since international markets seem to play a subordinate role for them, whereby the calculated CAGRs suggest that also on the domestic markets the future growth potential is quite low. Against this, Coastal \& maritime tourism, Renewable energy and especially Shipbuilding \& ship repair from SBSR show the greatest future growth potential in the context of international markets.

Concerning the internationalisation efforts, especially for companies from Germany and Sweden as well as at all in the case of the sub-sectors Aquaculture, Biotechnology, Fishery, Mineral resources as well as Offshore oil \& gas urgent need for actions were identified in this study. Since also the future potential in case of the Transport sector cannot convince, this sub-sector must be also considered to this low performance group. Hence, in order to systematically foster Blue Growth in the SBSR, particularly these sub-sectors need to be supported.

However, since turnover growth rates over $20 \%(\mathrm{hi}=7)$ had been considered as outliers in this study, it can be concluded, that the conducted analysis of the future potential of the maritime economy in SBSR followed a more pessimistic perspective. The resulting advantage through this procedure can be seen in an increased probability that the findings are more closely related to realistic market conditions i.e. increased reliability. On the other hand, the potential disadvantage could be seen in the circumstance that this measure could have had an impairing effect on the resulting and interpreted CARGs, which at the same time might be regarded as a potential methodological limitation of the present study. On the other hand, the results that refer to the two sub-sectors Mineral resources as well as Offshore oil \& gas have only limited significance and validity, since both sub-sectors are underrepresented in the underlying sample of this study. Accordingly, this can be regarded as another methodological limitation that refers to the partial sample sizes of the sub-sectors Mineral resources as well as Offshore oil \& gas.

Nevertheless, the overall findings underpin the urgent need of the initiated EU-project INTERMARE South Baltic that aims to support the maritime economy in the SBSR by the creation of a network of companies and stakeholders under the common brand "INTERMARE South Baltic", which will be easily recognised in the region and in other European and global markets. Vice versa, it is in the future responsibility of project consortium and other stakeholders outside the project (i.e. investors, entrepreneurs, scientists, politicians, etc.) to adjust the future measures and activities in an appropriate way to overcome these identified grievances from this study. Through this, essential, crucial and necessary steps can be taken in order to ensure an effective promotion and sustainable growth of SMEs from the maritime economy in SBSR on international markets. This will most efficiently foster SMEs from the Blue Economy in SBSR in their efforts of internationalisation.

Hence, the present study contribute to regional development and policy issues through the identified and analysed trends and future growth potential of the maritime economy in SBSR. Future works should target to develop a common development strategy for the maritime industry of SBSR in order to reach a sustainable internationalisation of SMEs, since other competing regions and maritime clusters in Europe already implemented sustainability and marketing strategies. This present study delivers the well-needed essential input and further insights for these upcoming tasks. As an extra concluding remark, since in all investigated SBSR countries and among all Blue Economy sub-sectors, digitalisation was detected as the most important mega trend that is expected to have the greatest positive impact on the future growth potential, this aspect should be taken into account in the frame of related future studies.

\section{Acknowledgements}

The European Regional Development Fund (INTERREG VA South Baltic programme) within the project "INTERMARE South Baltic" has supported this research article. 


\section{References}

1. Diekmann, A. (2007) Empirische Sozialforschung: Grundlagen, Methoden, Anwendungen. 18. Aufl. Hamburg.

2. Döring, N., \& Bortz, J. (2016) Forschungsmethoden und Evaluation. Wiesbaden: Springerverlag.

3. Dutta, S., Lanvin, B., \& Wunsch-Vincent, S. (Eds.). (2018) Global innovation index 2018: energizing the world with innovation.

4. European Commission (EC) (2012) Blue Growth: opportunities for marine and maritime sustainable growth, https://eur-lex.europa.eu/legal-content/EN/TXT/PDF/?uri=CELEX:52012DC0494\&qid= $1557080861033 \&$ from=EN (accessed: December 2019).

5. European Commission (EC) (2013a) Regional policy for smart growth of SMEs: Guide for Managing Authorities and bodies in charge of the development and implementation of Research and Innovation Strategies for Smart Specialisation,

http://ec.europa.eu/regional_policy/sources/docgener/studies/pdf/sme_guide/sme_guide_en.pdf (accessed: December 2019).

6. European Commission (EC) (2013b) Entrepreneurship 2020 Action plan: Reigniting the entrepreneurial spirit in Europe,

https://eur-lex.europa.eu/LexUriServ/LexUriServ.do?uri=COM:2012:0795:FIN:EN:PDF， (accessed: December 2019).

7. European Commission (EC) (2014) Blue Growth, https://ec.europa.eu/assets/mare/infographics/ (accessed: December 2019).

8. European Commission (EC) (2017) European Innovation Scoreboard, http://ec.europa.eu/DocsRoom/documents/24829 (accessed: December 2019).

9. European Commission (EC) (2018a) Small and medium-sized enterprises: Fact Sheets on the European Union - 2019, http://www.europarl.europa.eu/ftu/pdf/en/FTU_2.4.2.pdf (accessed: December 2019).

10. European Commission (EC) (2018b) EU Strategy for the Baltic Sea Region, https://ec.europa.eu/regional_policy/sources/cooperate/baltic/pdf/factsheet/factsheet_eusbr_en.pdf (accessed: December 2019).

11. European Commission (EC) (2019) Blue growth, https://ec.europa.eu/maritimeaffairs/policy/blue_growth_en (accessed: December 2019).

12. Eurostat (2018). Statistics on small and medium-sized enterprises: Statistics Explained, https://ec.europa.eu/eurostat/statistics-explained/pdfscache/45509.pdf (accessed: December 2019).

13. Gerlitz, L., Philipp, R., \& Beifert, A. (2017, October) Smart and Sustainable Cross-Sectoral Stakeholder Integration into Macro-Regional LNG Value Chain. In: International Conference on Reliability and Statistics in Transportation and Communication, pp. 112-126. Springer, Cham. https://www.researchgate.net/publication/319242333 (accessed: December 2019).

14. Goddard, J. (2000) The Response of HEIs to Regional Needs, http://www.oecd.org/dataoecd/40/25/34407585.pdf (accessed: December 2019).

15. Goddard, J. (1997) Universities and Regional Development: An Overview. The background paper for the OECD Project on The Response of Higher Education to Regional needs.

16. Henesey, L. \& Philipp, R. (2019, November) Evaluating LNG Bunkering Automation Technology. In: Casaca (eds.): 2019 World of Shipping Portugal, An International Research Conference on Maritime Affairs, Carcavelos, https://www.researchgate.net/publication/336899809 (accessed: December 2019)

17. Ketels, C., Pedersen, H. J., \& Olsson, M. (2017) State of the Region Report 2017: The Top of Europe-A Competitive Baltic Sea Region Ready for the Future? Baltic Development Forum.

18. Kromrey, H. (2013). Empirische Sozialforschung: Modelle und Methoden der standardisierten Datenerhebung und Datenauswertung (Vol. 1040). Springer-Verlag.

19. Madjidian, J., Gerlitz, L., Paulauskas, V., Jankowski, S., Henesey, L., Ölcer, A., Dalaklis, D., Ballini, F., Kitada, M. \& Philipp, R. (2017) Developing a strategy for LNG powered transport corridors in the Baltic Sea Region.

20. Meyer, C., Olaniyi, E. O., Philipp, R. \& Prause, G. (2020, January) A Holistic Assessment Approach For Clean Shipping Investments. $14^{\text {th }}$ International Conference on Operations Research, At: Universidad de La Habana, https://www.researchgate.net/publication/338558223 (accessed: December 2019).

21. O'Leary, Z. (2017) The essential guide to doing your research project. Sage.

22. Philipp, R., Gerlitz, L. \& Moldabekova, A. (2020, January) Small and Medium-Sized Seaports on the Digital Track: Tracing Digitalisation across the South Baltic Region by Innovative Auditing 
Procedures. In: International Conference on Reliability and Statistics in Transportation and Communication (forthcoming). Springer, Cham.

23. Philipp, R., Gerlitz, L. \& Prause, G. (2018) Regionale Häfen auf Digitalisierungskurs: Intelligentes Wachstum und nachhaltige Wertschöpfung entlang der kleinen und mittel-großen Häfen des Ostseeraumes, In: Cleve, Alde, Wißotzki (eds.): Proceedings of WiWiTa 2018 Conference, 77-86, Wismar, ISBN 978-3-942100-58-8, https://www.researchgate.net/publication/326113557 (accessed: December 2019).

24. Philipp, R., Gerlitz, L. \& Prause, G. (2019b, May) Smart Contracts for Entrepreneurial Collaboration in Logistics Networks. In: $11^{\text {th }}$ International Scientific Conference "New Challenges of Economic and Business Development - 2019: Incentives for Sustainable Economic Growth". At: University of Latvia - Riga, https://www.researchgate.net/publication/336316066 (accessed: December 2019).

25. Philipp, R., Ozarska, A., \& Prause, G. (2019a) Sustainable Electronic Product Development in the Baltic Sea Region: A Regional Gap Analysis of Lab Testing Services. Environmental and Climate Technologies, 23(3), 85-100. doi: 10.2478/rtuect-2019-0081

26. Philipp, R., Prause, G. \& Gerlitz, L. (2019c) Blockchain and Smart Contracts for Entrepreneurial Collaboration in Maritime Supply Chains, Transport and Telecommunication, 20(4), 365-378. doi: 10.2478/ttj-2019-0030

27. Porter M. E. (2000) Locations, clusters, and company strategy. The Oxford handbook of economic geography. UK: Oxford, 2000: 253, 274.

28. Prause, G., Gerlitz, L., \& Hoffmann, T. (2018) Design protection in managing sustainable userdriven innovation in SMEs. Journal of Japanese Management, Vol. 3(1).

29. Rüdiger, J., Heinz, A., Décieux, J. P., \& Eirmbter, W. (2011) Umfrage-Einführung in die Methoden der Umfrageforschung.

30. Schnell, R., Hill, P. B., \& Esser, E. (2004) Methoden der empirischen Sozialforschung.

31. zu Köcker, G. M. (2009) Clusters in Germany. Institute for Innovation and Technology, Berlin. 